\title{
Articulos
}

Construcción de paz en Colombia en el escenario de post acuerdo con la guerrilla de las FARC-EP

\section{Una reflexión acerca de retos y dilemas para el Trabajo Social}

Sebastián Correa

Estudiante de Trabajo Social y Filosofía

(Universidad Industrial de Santander)

Correo: sebaskorrea5@hotmail.com 
Resumen

Colombia ha vivido un conflicto armado de más de 50 años, llevando a la búsqueda de una salida política negociada en los últimos años, con el fin de construir la paz. El presente ensayo intentará reflexionar acerca de los retos y dilemas del Trabajo Social en los procesos de acompañamiento y reparación integral a víctimas, en el marco de la construcción de paz en Colombia, luego de firmado el acuerdo en la Habana entre las FARC y el gobierno nacional. Para tal fin, se abordarán algunas características generales de carácter sociohistórico del conflicto armado en Colombia, sus principales impactos y daños en la población, con el fin de plantear algunos retos de la acción profesional de Trabajo Social en contextos de construcción de paz.

\section{Palabras claves}

Conflicto armado - Reparación Integral a víctimas - Trabajo Social
Abstract

Colombia has experienced an armed conflict for more than 50 years, which has led in recent years to the search of a political outcome, to build peace. This paper attempts to reflect on the challenges and dilemmas of Social Work regarding the processes of accompaniment and integral reparation to victims, within the framework of peacebuilding in Colombia, after the agreement was signed in Havana between the FARC-EP and the national government. To this end, some general socio-historical characteristics of the armed conflict in Colombia, their main impacts and damages to the population will be addressed, to make light of some challenges concerning the professional action of Social Work in peace-building contexts.

Keywords

Armed conflict - Integral reparation to victims - Social Work 
"Es un pueblo muy paciente un pueblo

que espera sesenta y cinco, setenta, cien años por la paz.

Cien años de soledad.

Un pueblo que trabaja, que confía en Dios, que sueña con un futuro digno y feliz, porque, a pesar de lo que digan los sondeos frívolos, no vive un presente digno y no vive un presente feliz”

William Ospina

\section{Introducción}

Colombia se encuentra en un proceso de terminación del conflicto armado, debido, por un lado, al proceso de paz iniciado por el gobierno nacional y las Fuerzas Armadas Revolucionarias de Colombia (FARC) desde el año 2012, que finalizó su etapa de negociación con el Acuerdo Final para la Terminación del Conflicto y la Construcción de una Paz Estable y Duradera, firmado el 24 de noviembre de 2016, que dio paso - después de su refrendación-a la etapa de implementación de los acuerdos. Asimismo, desde febrero de 2017 el gobierno colombiano instauró una mesa de Negociación con la guerrilla del Ejército de Liberación Nacional (ELN), buscando como lo ha afirmado el presidente Juan Manuel Santos en diferentes medios de comunicación, una "paz completa". Teniendo en cuenta lo anterior, el presente ensayo busca reflexionar acerca de los retos y desafíos que tiene el Trabajo Social, como profesión-disciplina de las ciencias sociales y humanas en la construcción de paz en Colombia, luego de firmados los acuerdos de la Habana (Cuba) entre las FARC y el gobierno Nacional y la posible firma con el ELN.

En la primera parte del artículo, se abordarán algunos aspectos generales del contexto histórico en que se desarrolló el conflicto armado y sus efectos e impactos más notorios sobre la población colombiana. Por otro lado, se revisarán los marcos jurídicos que pueden 
orientar la acción profesional de Trabajo Social en lo que compete a la reparación integral a víctimas. Seguidamente, se reflexionará acerca de los retos y dilemas del ejercicio profesional de Trabajo Social, teniendo en cuenta sus principios y las exigencias de la sociedad colombiana contemporánea en el marco de los posacuerdos. Por último, se establecerán conclusiones, con el fin de enriquecer el debate sobre el ejercicio profesional del Trabajo Social en Colombia y América Latina.

\section{Contexto histórico e impactos sobre la población colombiana}

Colombia se ha caracterizado por sus altos niveles de conflictividad social, manifestados en guerras y confrontaciones directas entre los pobladores de este país debido, principalmente, a problemas sociales, económicos y culturales como: la falta de distribución equitativa de la tierra, el abandono generalizado del Estado en el territorio colombiano, la polarización política y, recientemente, el auge y consolidación del narcotráfico. Sin embargo, es en el siglo XX donde Colombia vive los más altos índices de violencia directa, debido al surgimiento de un conflicto armado interno, que tiene sus antecedentes en el período denominado "La Violencia", comprendido entre 1948 y 1958, en el cual ocurrieron asesinatos y agresiones entre simpatizantes del partido conservador y el partido liberal debido a la constante pugna por el poder. Al respecto, el Grupo de Memoria Histórica (en adelante, GMH) afirma "dentro de los partidos políticos se constituyeron agrupaciones armadas con diferentes niveles de organización: de un lado, la policía chulavitan y los pájaros (asesinos a sueldo), al servicio del Gobierno Conservador; del otro, las guerrillas liberales y las autodefensas comunistas" (2013:112). Entre los asesinatos más emblemáticos, se encuentra el magnicidio del caudillo Jorge Eliécer Gaitán el 9 de abril de 1948, líder carismático y con amplio apoyo popular, quien fue asesinado debido a la distancia que había tomado de las ideas tradicionales del Partido Liberal colombia- 
no, adoptando posturas socialistas que representaban una amenaza para el orden social vigente. Este asesinato desencadenó el hecho histórico conocido como el "Bogotazo", que intensificó la violencia en la población colombiana.

Como respuesta a la polarización política que vivía el país, en 1958 el presidente de Colombia, el general Rojas Pinilla, tomó la decisión de llegar a un acuerdo entre los simpatizantes del partido Conservador y Liberal, con el fin de reducir los altos índices de violencia, para ello conformaron una coalición llamada el Frente Nacional, en la que acordaron alternarse por partes iguales los cargos públicos de representación, el cual duró 16 años. Sin embargo, a pesar de los sucesos violentos que se evitaron con dicho acuerdo, esta medida de alternancia en el poder es catalogada como negativa por algunos estudiosos del conflicto armado en Colombia, debido a que se da un cierre del universo político, como lo afirma Sergio de Zubiría, mediante la "represión contra las disidencias políticas, los partidos de oposición y los movimientos sociales autónomos" (2015:223) negando expresiones políticas afines a las ideas socialistas, precisamente en auge debido al triunfo de la Revolución Cubana.

En los años sesenta nacen las guerrillas de las FARC, el ELN y el Ejército Popular de Liberación (EPL), las cuales se adscriben a unas corrientes marxistas-leninistas pro revolución cubana y china, canalizando el descontento social, producto del abandono estatal, la desigualdad social, la imposibilidad de acceso a la tierra, siendo los campesinos los más afectados. Sin embargo, en los primeros años estos grupos armados no lograron mayor impacto a nivel militar, según el GMH “durante las décadas de 1960 y 1970, la lucha armada no tuvo una particular visibilidad en la escena nacional, debido al confinamiento de los grupos guerrilleros en zonas periféricas y al carácter incipiente de dichas organizaciones, tanto en el plano político como en el militar" (2013:127). Asimismo, en 1974 producto del fraude en las elecciones presidenciales de 1970 surge la guerrilla del Movimiento 19 de Abril (M-19) con un enfoque más urbano que rural.

Es así como, al finalizar el período presidencial de Alfonso López Michelsen, el 14 de septiembre de 1977 se da un gran paro cívico en 
el país, convocado por sectores populares, debido a la profunda crisis económica y social en que se encontraba Colombia, el cual fue reprimido fuertemente por las fuerzas militares que evidenciaron su postura anticomunista (GMH, 2013:132). En concordancia con lo anterior, el presidente Turbay Ayala en 1982 dicta la medida del Estatuto de Seguridad Nacional, que buscaba la persecución política de toda expresión diferente crítica acerca del orden vigente en Colombia, teniendo en cuenta el imaginario del enemigo interno y la mentalidad contrainsurgente que vivía la institucionalidad colombiana. Al respecto, Jairo Estrada afirma: "el sistema capitalista colombiano imperante, en respuesta a los movimientos cívicos y guerrilleros que buscaban la transformación del país, activó con toda fuerza como dispositivo de preservación sistémica el terrorismo de Estado cuya expresión normativa estuvo en el Estatuto de Seguridad, impuesto durante el gobierno de Turbay Ayala (1978-1982). Siguiendo la experiencia antisubversiva de las dictaduras del Cono Sur, las detenciones arbitrarias, la tortura, la desaparición forzada se erigieron como armas preciadas del combate contra el enemigo interno" (2015:325).

Lo anteriormente citado llevó a la guerrilla de las FARC a la reorientación de su política militar, pasando de una estrategia defensiva a una ofensiva, con el objetivo de expansión territorial que permitiera la toma del poder en Colombia y en respuesta al Estatuto de Seguridad Nacional. Al respecto, GMH afirma: “en su VII Conferencia, realizada en 1982, habían decidido pasar de ser una guerrilla defensiva para convertirse en una ofensiva, en un contexto endurecido por el Estatuto de Seguridad de Turbay Ayala” (2013:135).

Por otro lado, en 1984 producto de los acuerdos de la Uribe entre el gobierno de Belisario Betancourt y las FARC, se da origen al partido político de la Unión Patriótica, que surge como propuesta para realizar disidencia política por medios democráticos. Sin embargo, en los siguientes años se da el asesinato sistemático de los miembros del partido por parte de los grupos paramilitares y miembros del Estado, generando un genocidio político que causó una posterior intensificación del conflicto armado, debido a que este experimento impedía pensar la posibilidad de llegar a cargos de representación, por medios 
democráticos, a los grupos políticos alzados en armas. De esta manera, según Sergio de Zubiría, no sólo se asesinó físicamente a sus militantes, sino también "este tipo de victimización colectiva tiene la característica que está eliminando política y culturalmente otras sociedades posibles y proyectos políticos alternativos; no se trata de la muerte física individual sino de asesinar los sueños políticos colectivos de comunidades enteras" (2014:222).

Es necesario resaltar que en la década del ochenta se da el auge y consolidación de la economía del narcotráfico, permeando las dinámicas del conflicto armado, generando muertes, zozobra y temor en la población colombiana, es en este contexto donde se dan a conocer los carteles de Medellín y de Cali. Asimismo, surgen los grupos paramilitares, en sus inicios grupos de seguridad privada que tenían como fin la protección de la propiedad privada y la eliminación de los grupos comunistas que eran entendidos como una amenaza; en estos grupos se resaltan líderes como los hermanos Castaño, Rojas, Buitrago y Hernán Giraldo, Salvatore Mancuso, entre otros. Es necesario precisar que estos ejércitos actuaron con la complicidad de la fuerza pública; al respecto Uprimmy afirma que "las acciones paramilitares no siempre fueron perpetradas por estructuras armadas constituidas al margen de la ley, sino que en muchos casos fueron acciones clandestinas de sectores radicales de las Fuerzas Militares, o simplemente acciones sicariales que respondían a alianzas funcionales y coyunturales entre distintos actores económicos, políticos y militares que no apuntaban a la conformación de grupos o comandos permanentes" (2013:140).

Sin embargo, en el año 1996 estos grupos dieron origen a las Autodefensas Unidas de Colombia (AUC), ejército paramilitar de extrema derecha, encabezado por los hermanos Castaño y considerado uno de los principales actores que más víctimas ha dejado en el conflicto armado. En cuanto a su naturaleza, Marcos Palacios sostiene que "los paramilitares han sido los grupos más elusivos del conflicto armado colombiano. Nacen y pelechan en los intersticios del narcotráfico, el latifundismo, el clientelismo y las prácticas de la contrainsurgencia. Prima facie aparecen con el carácter reactivo de 
fuerzas supletorias del Estado ante la acción guerrillera; como dijera «Tirofijo» en su discurso de la "silla vacía», son los hijos legítimos del Estado" (2014:236).

En 1991 se promulga la nueva constitución colombiana, acompañada de la desmovilización del EPL y el M-19. No obstante, a pesar del reconocimiento de diferentes derechos en dicha carta magna, en los siguientes años se da una articulación entre grupos paramilitares, empresarios y algunos miembros del Estado con el fin de derrotar a las guerrillas, generando altos índices de violencia. Es así como se afirma que entre 1996 y 2005, la guerra alcanzó su máxima expresión, extensión y niveles de victimización. El conflicto armado se transformó en una disputa a sangre y fuego por las tierras, el territorio y el poder local. Se trata de un período en el que la relación de los actores armados con la población civil se transformó. En lugar de la persuasión, se instalaron la intimidación y la agresión, la muerte y el destierro (GMH, 2013:156).

En el período presidencial de Andrés Pastrana, se llevó a cabo un proceso de negociación entre el gobierno y las FARC, conocido como los Diálogos del Caguán. Sin embargo, su fracaso generó el imaginario en la sociedad colombiana de la imposibilidad de una salida política negociada al conflicto, siendo la guerra la única opción. Precisamente en este contexto, es elegido Álvaro Uribe Vélez, quien gobierna durante dos períodos (2001-2010), centrando su gobierno en su política de seguridad democrática, que buscaba una derrota militar de las guerrillas presentes en el país. En el desarrollo de esta política de seguridad, se dan alianzas entre sectores económicos, políticos, sociales y militares que buscaban el posicionamiento militar y político del paramilitarismo en Colombia, debido a los intereses comunes en cuanto a la defensa de la propiedad privada y la ideología contrainsurgente que ha primado en Colombia desde el siglo pasado.

Por ello en Colombia, producto del aumento de la ofensiva paramilitar, se da la mayor cifra de desplazamiento forzado de la historia. Según Acnur Colombia, ocupa el segundo lugar en el mundo por el número de desplazados internos y el octavo lugar por el número de refugiados en el exterior. A su vez, debido a los incentivos otorga- 
dos a militares por guerrilleros dados de baja, bandera central de la política de seguridad democrática, se las ejecuciones extra judiciales de civiles o falsos positivos, modalidad que consistía en el asesinato de jóvenes civiles, con el fin de hacerlos pasar como guerrilleros y de esta forma mostrar a la opinión pública los resultados en su política guerrerista (este suceso se dio a conocer en el año 2008, siendo Juan Manuel Santos Ministro de Defensa). Entre 2003 y 2006 se da un proceso de desarme de los grupos paramilitares, conocido como Las Conversaciones de Ralito, donde algunos bloques de las AUC se desmovilizan, acogiéndose a la Ley de Justicia y Paz. Sin embargo, en los años posteriores se vivió un rearme de estos paramilitares, que perdura hasta hoy.

Finalmente, en 2010 Juan Manuel Santos Calderón es elegido presidente de Colombia con la promesa de continuar las políticas guerreristas de su antecesor, pero, a mediados de su primer mandato toma distancia y decide buscar una salida negociada al conflicto armado con las FARC. Para ello, el 26 de agosto del 2012 se firma el "Acuerdo para la Terminación del Conflicto y la Construcción de una Paz Estable y Duradera”, en la cual se estipuló la agenda de negociación entre las partes y se definieron los puntos a discutir, a saber: política de desarrollo integral, participación política, fin del conflicto, solución al problema de las drogas ilícitas, víctimas e implementación, verificación y refrendación de los acuerdos.

Más adelante, el 26 de junio del 2016, las partes firman un acuerdo que buscó ser refrendado a través de un plebiscito, el 2 de octubre de 2016, en el que ganó el No. Frente a ello, la mesa de negociaciones decidió realizar algunos cambios teniendo en cuenta las críticas que se realizaban al acuerdo, lo que dio como resultado la firma de un nuevo texto el 24 de noviembre de 2016, que fue refrendado mediante el Congreso de la República. El 7 de febrero de 2017 el gobierno de Santos dio inicio a la fase pública de negociación con el ELN, que busca el fin del conflicto armado en Colombia con una de las guerrillas más viejas del hemisferio occidental, con el objetivo de buscar una "paz completa" que dé paso a la construcción de paz. 
Es necesario precisar que la búsqueda de la paz no es sólo una apuesta de las élites políticas, ya que la sociedad colombiana ha jugado un papel importante mediante la movilización social por la paz, en la cual han participado asociaciones de víctimas, movimientos estudiantiles y comunidades campesinas ${ }^{1}$.

La violencia que ha vivido Colombia por más de 50 años ha dejado un total de 8.022.919 víctimas, según el Registro Único de Víctimas, y un total de 6.371 .695 sujetos de atención, debido a la perpetración de modalidades de violencia como: asesinatos, masacres, sevicia y tortura, desapariciones forzadas, secuestros, despojos y extorsiones, violencia sexual, reclutamiento ilícito, mina antipersonal, ataques a bienes civiles, atentados terroristas, entre otros, todas violatorias del derecho internacional humanitario, los derechos humanos, generando graves secuelas en las familias, grupos y comunidades.

Una de las particularidades del conflicto armado es la afectación diferenciada dependiendo de la zona del país, debido a que existen territorios estratégicos para los grupos armados. Al respecto, Jorge Giraldo afirma que "el $48 \%$ de los episodios de victimización tuvo lugar en siete departamentos: Antioquía, Cauca, Valle del Cauca, Ariño, Cesar, Norte de Santander y Meta" (2015:86). Por otro lado, debido a la diversidad étnica colombiana, las comunidades indígenas y afrocolombianas se han visto afectadas. El informe del PNUD afirma que entre 1996 y 2009, 1190 indígenas fueron asesinados. Estas cifras se hacen más dramáticas cuando se considera que, tal y como lo afirma la ONIC, 102 pueblos indígenas se encuentran en riesgo de desaparecer, de los cuales 32 cuentan con menos de 500 personas (GMH, 2013:278).

Estos hechos dejan en los diversos grupos poblacionales colombianos, diferentes daños psicológicos, políticos y socioculturales. Según

1 Se destacan experiencias como San José de Apartadó, que desde 1997 decidió conformase como Comunidad de Paz e impide la entrada de cualquier actor armado en la zona y, a pesar del asesinato de varios de sus pobladores, sigue resistiendo desde la No Violencia. También la experiencia de la Zona de Reserva Campesina de la Asociación Campesina de Valle del Rio Cimitarra, que mediante su apuesta política de permanencia en el territorio ha resistido no violentamente a las confrontaciones del conflicto armado, siendo merecedores en 2010 del Premio Nacional de Paz (Cely, 2015:17). Son sólo dos ejemplos de las diferentes experiencias que existen desde la población colombiana hacia la construcción de paz. 
el GMH, "los impactos psicológicos deterioran las relaciones interpersonales y la salud física; las pérdidas económicas generan inestabilidad emocional; los impactos colectivos y el daño a las redes sociales y comunitarias afectan las capacidades y posibilidades individuales" (2013:260).

Uno de los daños e impactos a nivel sociocultural es la destrucción del tejido social, el deterioro de las prácticas comunitarias y colectivas, debido al miedo y zozobra instaurado por la violencia. Según Francisco Gutiérrez, "el conflicto destruyó de manera masiva el tejido social, tradiciones positivas y redes de confianza. En la medida en que estuvo asociado a un brusco aumento de la criminalización de la vida pública y la propiedad sobre la tierra, también, tuvo un efecto deletéreo sobre la confianza de los colombianos en sus conciudadanos y en las instituciones" (2015:557).

A raíz de lo anterior, en la sociedad se presenta una alta polarización política, desconfianza y miedo, donde todo aquel que piense diferente es considerado como un enemigo que debe ser deshumanizado y eliminado. La imposición "de variadas formas y dispositivos de regulación social que han naturalizado el ejercicio de la violencia, ha pretendido quebrar toda expresión de cooperación y solidaridad y ensanchado una especie de fascismo social que no excluye la liquidación del contradictor devenido en enemigo" (Estrada, 2015:356).

Por otro lado, a nivel psicológico y emocional son múltiples los daños debido a los hechos victimizantes, que generan sentimientos de rabia, dolor, culpa, vergüenza, miedo, zozobra, impotencia, entre otros. Por ejemplo, en crímenes como las masacres, torturas, violencia sexual, ejecuciones extrajudiciales y desapariciones forzadas, según GMH, "son hechos que marcan las historias individuales y colectivas, que rompen abruptamente el curso de las vidas porque arrebatan la certidumbre de habitar un mundo conocido y ponen en crisis creencias, relaciones y, en general, todos los aspectos que son fuente de sentido y de soporte para la existencia" (2013:267).Sobre las consideraciones anteriores, vale la pena resaltar los daños e impactos causados producto de la ineficiencia estatal y la reparación limitada exclusivamente a una labor económica. De la misma manera, 
producto de la impunidad y la continua re victimización a la que es sometida la población sujeta de atención, según el GMH, "vivir una situación de impunidad puede provocar sentimientos de odio, miedo o deseos de venganza, especialmente cuando las víctimas constatan que los victimarios continúan libres, con igual o mayor poder y autoridad, o cuando reciben penas o sanciones que no corresponden a la gravedad de los crímenes cometidos” (2013:324).

Ley de víctimas y Acuerdo general de víctimas en la mesa de la Habana

El gobierno colombiano ha definido un marco jurídico para el restablecimiento de la población colombiana víctima del conflicto armado, creando acuerdos como la Ley 1448 de 2011 y el Acuerdo sobre víctimas, que establece un Sistema Integral de Verdad, Justicia, Reparación y No Repetición. La ley 1448 en su artículo 3 define a las víctimas como "aquellas personas que individual o colectivamente hayan sufrido un daño por hechos ocurridos a partir del 10 de enero de 1985, como consecuencia de infracciones al Derecho Internacional Humanitario o de violaciones graves y manifiestas a las normas internacionales de Derechos Humanos, ocurridas con ocasión del conflicto armado interno". Esto plantea una limitación de carácter temporal, donde quedan excluidas todas aquellas personas que hayan sido víctimas antes de la fecha establecida.

En cuanto a la reparación integral, la Ley "comprende las medidas de restitución, indemnización, rehabilitación, satisfacción y garantías de no repetición, en sus dimensiones individual, colectiva, material, moral y simbólica" debido a los altos índices del desplazamiento forzado en Colombia; el título III y capítulo II especifican el marco jurídico para la atención a víctimas en esta modalidad de violencia. Asimismo, se destaca la creación de un Sistema Nacional de Atención y Reparación Integral a las Víctimas en el título V y capítulo III.

Por otro lado, en el Acuerdo Final de Terminación del Conflicto y la Construcción de una Paz Estable y Duradera, firmado el 26 de no- 
viembre de 2016, se establece un Sistema Integral de Verdad, Justicia, Reparación y No Repetición, cuyos objetivos específicos son: satisfacción de los derechos de las víctimas, rendición de cuentas, no repetición, enfoque territorial y de género, seguridad jurídica, convivencia y reconciliación, legitimidad (GNC, FARC y PG, 2016).

\section{Retos y dilemas del Trabajo Social}

En el actual panorama social que vive Colombia, los y las profesionales en ciencias sociales y humanas están llamados a dar un aporte desde su campo de acción a la construcción de paz. Entre estas se encuentran los procesos de acompañamiento e intervención desde el Trabajo Social, como una profesión-disciplina que se caracteriza por su potencial interdisciplinar y su mirada holística de las problemáticas sociales, abordada desde una postura ético-política. Al respecto, en cuanto al ejercicio y definición del Trabajo Social, la FITS afirma que "el Trabajo Social es una profesión basada en la práctica y una disciplina académica que promueve el cambio y el desarrollo social, la cohesión social, y el fortalecimiento y la liberación de las personas. Los principios de la justicia social, los derechos humanos, la responsabilidad colectiva y el respeto a la diversidad son fundamentales para el Trabajo Social. Respaldada por las teorías del Trabajo Social, las ciencias sociales, las humanidades y los conocimientos indígenas, el Trabajo Social involucra a las personas y las estructuras para hacer frente a desafíos de la vida y aumentar el bienestar".

Teniendo en cuenta los principios que orientan la profesión, vale la pena preguntarse ¿a qué está llamada en el contexto de post acuerdos en Colombia? Al respecto, Martha Nubia Bello, sostiene que en escenarios de violencia política como los que ha vivido el país por cuenta del conflicto armado, el Trabajo Social está llamado a la "construcción de comunidad, el fortalecimiento de autonomías e identidades, la reconstrucción de tejidos sociales y de sujetos comunitarios, el fomento de la participación y de la organización” (2005:16). 
Por tanto, el Trabajo Social puede aportar a la construcción de paz, considerando sus principios, por un lado, desde su potencial investigativo, como disciplina adscrita a las ciencias sociales, de la mano con los estudios de paz, educación para la paz, género, decolonialismo y el enfoque de derechos, podrán permitir una comprensión holística y profunda del conflicto armado teniendo en cuenta sus complejidades específicas. Por otro lado, la práctica profesional, a través de los diversos métodos y metodologías, la formulación, implementación y ejecución de políticas públicas, permitirán el desarrollo de acciones sociales, gestadas desde y con las víctimas, encaminadas a la reconstrucción de tejido social, la promoción de la democracia, la defensa de los derechos humanos y la búsqueda de la justicia social en el marco de los post acuerdos.

Los retos del Trabajo Social en una sociedad fragmentada y gravemente afectada por la guerra son complejos, debido a la naturalización de la violencia en muchos ámbitos, por lo cual se deben pensar acciones profesionales encaminadas a la construcción de paz, desde y con las víctimas, buscando la reconstrucción del tejido social que se ha visto gravemente afectado, producto de las modalidades de violencia perpetradas en Colombia.

Teniendo en cuenta lo anterior, una de las principales fortalezas del Trabajo Social es su enfoque práctico, lo cual permite desarrollar procesos de intervención directamente con los actores. Al respecto, Loaiza afirma que "el Trabajo Social, al interactuar en contextos donde las relaciones humanas se dan, tiene un gran escenario para conocer, desde la base, cómo se construyen las relaciones entre los géneros y si éstas aportan o no a la construcción de paz, así como si esas interacciones están mediadas por la paz o por la violencia en la transformación de los conflictos. Es posible también hallar visiones y perspectivas desde los propios actores involucrados y desde sus cosmovisiones como base para lecturas diferentes de la realidad" (2015:103).

Por ello, el Trabajo Social al conocer la realidad desde los sujetos que la viven, debe plantearse procesos de acompañamiento y de reparación integral a víctimas concebidos más allá de lo institucio- 
nal, debido a que muchas veces esto se ve limitado. Sobre este punto, Bello afirma que "las víctimas requieren, además, apoyo a sus procesos organizativos y sus demandas de justicia. La justicia es un valor que traspasa la esfera institucional y legal y que abarca dinámicas y acciones del ámbito social y comunitario" (2014:176). De igual modo, Bello sostiene que enfoques como el psicosocial permiten una comprensión más holística e integral de los daños e impactos en las víctimas, teniendo en cuenta los diferentes contextos del conflicto armado: "un enfoque psicosocial debe, por tanto, considerar las situaciones concretas que ponen a la persona en determinada situación — tristeza, depresión, desinterés, dependencia, agresividad-y tratarla en el marco del contexto social, comunitario, familiar y personal que se valora en función de los riesgos, oportunidades, protecciones y vínculos que pueden afectar tanto positiva como negativamente la vivencia particular” (2009:25).

Otro de los retos es evitar la revictimización, en muchos casos generada por la impunidad, por tanto, el Trabajo Social debe ir más allá de la visión institucional, que muchas veces reproduce la violencia de forma estructural, que concibe a las personas como objetos, cifras y sujetos pasivos de atención, olvidando que son sujetos activos de derechos. Por ello, Bello advierte que "las víctimas, aquellos seres humanos a quienes se les arrebata la posibilidad de contar con las certezas y certidumbres mínimas que emergen de cierto ordenamiento institucional, social y simbólico, no son pacientes, dolientes, clientes, con quienes nos podemos relacionar desde la distancia y la indolencia, desde la objetividad y la asepsia" (2005:20).

Teniendo en cuenta lo anterior, es pertinente cuestionar el papel de supuesta objetividad y neutralidad que asumen algunos profesionales y superar la concepción pasiva de las víctimas a las que son sometidas desde el ámbito institucional y académico, debido a la visón técnicoinstrumental de las investigaciones e intervenciones profesionales que niegan las potencialidades y conocimientos que puede aportar cada ser humano a la transformación de su realidad.

En concordancia con lo anterior, Victoria Fontan, quien ha trabajado en diferentes países en escenarios post acuerdos y construcción 
de paz, advierte que es necesario ser críticos frente a los estudios de paz contemporáneos, debido a que la conciben desde una concepción mecánica, que legitima lógicas coloniales, a través de la reproducción de jerarquías, donde los profesionales son quienes "mandan", formular, hacen, piensan y ejercen una labor activa debido a su "superioridad intelectual", mientras que las víctimas y poblaciones afectadas ocupan una labor pasiva de obediencia. Por ello, plantea la necesidad de descolonizar la paz, lo cual "implica que la paz ya existe a nivel local, que no tiene que ser construida de acuerdo con los valores y el entendimiento que no son propios de ese entorno" (2005:49), rompiendo con la visión de que los profesionales formados en temas de paz y conflicto son aquellos mesías y salvadores que van a llevar la paz.

Considerando lo anterior, el profesional en Trabajo Social debe llevar a cabo su intervención profesional a través de técnicas y metodologías que faciliten y permitan la participación activa de los sujetos que hacen parte de cada realidad afectada por el conflicto armado, teniendo en cuenta que no debe imponer ni pre establecer valores y acciones a las personas, buscando de promover las potencialidades, conocimiento y saberes de las víctimas del conflicto armado, generando relaciones horizontales y democráticas que faciliten escenarios de reconstrucción del tejido social. Por ello, es necesario tener en cuenta herramientas como la educación popular y la sistematización de experiencias, que construyen conocimiento desde los sujetos.

En cuanto a procesos gestados desde la población víctima, Mellizo propone que, en los casos de desapariciones forzadas y ejecuciones extrajudiciales, “desde Trabajo Social, la recuperación de la memoria se presenta como un elemento central en la intervención psicosocial para la construcción de narraciones individuales y familiares y con sentido social" (2011:126), permitiendo el protagonismo de las voces de las víctimas, sus relatos e imaginarios para satisfacer los derechos más allá de lo económico-burocrático, debido a que a través de la movilización y construcción conjunta de conocimiento popular, las víctimas pasan a ser protagonistas de la transformación de sus realidades. 


\section{Conclusiones}

La firma de los acuerdos con las FARC y posiblemente con el ELN, genera en Colombia un escenario propicio para la construcción de paz, por tanto, profesiones como el Trabajo Social deben pensar los procesos de intervención y acompañamiento a víctimas desde la satisfacción de derechos. Para ello, en primera instancia, se debe hacer más énfasis en la investigación en Trabajo Social ligada a los estudios de paz, con perspectiva de género, decolonial. De la misma manera, las acciones profesionales deben tener un compromiso ético-político que permita desarrollar procesos acordes a los principios y fines de la profesión. El Trabajo Social debe trabajar con otras disciplinas de las ciencias sociales, lo que le permitirá abordar las problemáticas teniendo en cuenta diversos aspectos propios de la complejidad de la implementación de los acuerdos.

Por otro lado, los procesos de acompañamiento y satisfacción de derechos deben llevarse a cabo desde relaciones horizontales, donde las víctimas pasen de ser objetos de intervención, clientes, a sujetos de acción y transformación de sus realidades, evitando la revictimización y negación de las capacidades de los sujetos que generan lógicas de violencia simbólica.

Finalmente, el Trabajo Social colombiano debe ejercerse desde una postura crítica y comprometida con un enfoque ético-político, siendo necesaria la exigencia, a través de la movilización social, del cumplimiento por parte del Estado de la implementación de los acuerdos y la búsqueda de reformas estructurales al sistema económico y político del país, dejando de un lado la supuesta neutralidad y tomando postura teniendo en cuenta las demandas de la población colombiana.

\section{Referencias bibliográficas}

BELLO ALBARRACIN, M. “Trabajo Social en contextos de violencia política”, en: Revista de Trabajo Social, $N^{\circ}$ 7. Universidad Nacional de Colombia, enero 2005. Pp. 9-20. [En línea: 10/04/2017] Disponible en: http://revistas.unal.edu.co/index.php/tsocial/ article/view/8472/9116 
CELY LOPEZ, P. "Memorias de movilización, organización y resistencia campesina en medio de la violencia sociopolítica y el conflicto armado interno en Colombia. El caso de la Asociación Campesina del Valle del río Cimitarra (ACVC)", en: Revista Aletheia. Vol. 5, N 10. Bogotá, abril 2015. Pp. 1-21. [En línea: 15/05/2017] Disponible en: http://www. aletheia.fahce.unlp.edu.ar/numeros/numero-10/pdfs/Cely.\%20Dossier.\%20Articulo.pdf.

CIFUENTES PATIÑO, M. R. "Niñez y juventud, víctimas del conflicto armado: retos para el trabajo social”, en: Revista Tendencias \& Retos. Vol. 20, N 1. Enero-junio 2015. Pp. 161-177.

ESTRADA, J. Contribución al Entendimiento del Conflicto Armado en Colombia: Acumulación Capitalista, Dominación de Clase y Rebelión Armada. Bogotá, Ediciones Desde Abajo, 2015.

FEDERACION INTERNACIONAL DE TRABAJADORES SOCIALES (IFSW). Propuesta de Definición Global del Trabajo Social. [En línea: 10/07/2017] Disponible en: http://ifsw.org/propuesta-de-definicion-global-del-trabajo-social/

FONTAN, V. C. Descolonización de la paz. Santiago de Cali, Colombia, Pontificia Universidad Javeriana, Sello Editorial Javeriano, 2013.

GRUPO NACIONAL DE MEMORIA HISTÓRICA. ¡BASTA YA! Colombia: Memorias de guerra y dignidad. Bogotá, Imprenta Nacional, 2013.

GOBIERNO NACIONAL de COLOMBIA, FARC-EP y PAÍSES GARANTES. Acuerdo General para la Terminación del Conflicto y la Construcción de una Paz Estable y Duradera. Acuerdo General. La Habana, Cuba, 26 de agosto de 2012. [En línea: 13/06/2017] Disponible en: https://www.mesadeconversaciones.com.co/sites/default/files/ AcuerdoGeneralTerminacionConflicto.pdf

GOBIERNO NACIONAL de COLOMBIA, FARC-EP y PAÍSES GARANTES. Acuerdo final para la terminación del conflicto y la construcción de una paz estable y duradera. 2016. [En línea: 16/07/2017] Disponible en: https://www.mesadeconversaciones.com.co/ sites/default/files/24-1480106030.11-1480106030.2016nuevoacuerdofinal-1480106030. pdf

LOAIZA, A.M. "Investigación para la paz y trabajo social: construcción de una cultura para las paces con perspectiva de género", en: Revista Eleuthera, $N^{\circ} 12$, 2015. Pp. 89111. [En línea: 12/12/2016] Disponible en: http://eleuthera.ucaldas.edu.co/downloads/ Eleuthera12_5.pdf.

MELLIZO ROJAS, W. "Desaparición Forzada y ejecuciones extrajudiciales: Retos y dilemas para el Trabajo Social”, en: Revista Colombiana de Trabajo Social. Editorial Universidad del Valle, Vol. 23, 2011. Pp. 107-129.

PIZARRO, E. Contribución al Entendimiento del Conflicto Armado en Colombia: Una lectura múltiple y pluralista de la historia. Bogotá, Ediciones Desde Abajo, 2015.

REGISTRO ÚNICO DE VÍCTIMAS (RUV). Red Nacional de Información. [En línea: 12/02/2017]. Disponible en: http://rni.unidadvictimas.gov.co/?q=node/107. 
REPÚBLICA DE COLOMBIA. LEY nº 1448. 10 de junio de 2011. [En línea: 10/12/2016] Disponible en: http://secretariasenado.gov.co/senado/basedoc/ley_1448_2011.

htmlZUBIRIA, S. Contribución al Entendimiento del Conflicto Armado en Colombia: Dimensiones políticas y culturales en el conflicto armado. Bogotá, Ediciones Desde Abajo, 2015. 